\title{
Desempenho de cultivares de alface em cultivo hidropônico sob dois níveis de condutividade elétrica
}

\author{
Adriana G Magalhães'; Dimas Menezes'; Luciane V Resende²; Egídio Bezerra Neto³ \\ ${ }^{1}$ UFRPE, Dep ${ }^{\text {to }}$. Agronomia, Av. Dom Manoel de Medeiros s/n, 52171-900 Recife-PE; ${ }^{2}$ UFLA, C. Postal 37, $37200-000$ Lavras-MG; \\ 33FRPE, Dep. Química; agmguedes@gmail.com; dimas@depa.ufrpe.br; luciane.vilela@dag.ufla.br; egidio@dq.ufrpe.br
}

\section{RESUMO}

O objetivo do trabalho foi comparar cultivares de alface de folhas soltas lisas, submetidas a estresse osmótico em soluções nutritivas sob cultivo hidropônico. Foram realizados dois experimentos, cada um com uma condutividade elétrica (C.E.) de $2,0 \mathrm{dS} \mathrm{m}^{-1}$ e $2,5 \mathrm{dS}$ $\mathrm{m}^{-1}$. Os tratamentos foram as cultivares de alface Babá de Verão, Floresta, Luisa, Manoa, Regina 579, Saia Véia e Vitória Verdinha. O delineamento experimental foi blocos casualizados, com três repetições. A colheita foi feita aos 45 dias após a semeadura. Nenhuma cultivar se destacou no conjunto das características avaliadas, embora a Manoa tenha apresentado o maior índice de queima de bordas das folhas, sem diferir estatisticamente da Saia Véia e Babá de Verão. As cultivares Regina 579 e Vitória Verdinha são as preferidas dos produtores hidropônico de Pernambuco, devido à falta de genótipos mais adaptados a essa modalidade de cultivo, e por apresentarem folhas lisas, levemente enrugadas e de textura macia.

Palavras-chave: Lactuca sativa L., queima das bordas, cultivo hidropônico.

\begin{abstract}
Evaluation of two electric conductivity levels on the hidroponic cultivation of lettuce
\end{abstract}

The aim of this work was to compare loose-leaf lettuce cultivars submitted to osmotic stress in nutrient solutions in hydroponic culture. Two experiments were carried out, with electric conductivity of 2.0 or $2.5 \mathrm{dS} \mathrm{m}^{-1}$. The treatments were the cultivars Babá de Verão, Floresta, Luisa, Manoa, Regina 579, Saia Véia, and Vitória Verdinha. The experimental design was randomized blocks with three replications. Harvest was performed 45 days after sowing. None among the cultivars differed clearly on the characteristics evaluated. However, "Manoa" showed the highest rate of leaf-edge burning, without significant difference in comparison to "Saia Véia" and "Babá de Verão" for summer. The cultivars Regina 579 and Vitória Verdinha are preferred by the growers of hydroponic vegetables of Pernambuco, due to the lack of better genotypes for this type of cultivation and due to the presence of smooth slightly-wrinkled leaves with soft texture.

Keywords: Lactuca sativa L., tipburn, hydroponics.

(Recebido para publicação em 28 de novembro de 2008; aceito em 27 de agosto de 2010) (Received on November 28, 2008; accepted on August 27, 2010)

A cultura da alface (Lactuca sativa L.) é explorada em todo o território nacional e compõe parcela importante das hortaliças na dieta da população, tanto pelo sabor, pelo baixo custo e qualidade nutritiva, como fonte de vitaminas, sais minerais e fibras. Constitui-se na mais popular hortaliça dentre aquelas em que as folhas são consumidas cruas e ainda frescas (Fernandes et al., 2002; Cometti et al., 2004a).

Em Pernambuco, a alface está presente nos cinturões verdes das maiores cidades, concentrando-se em Vitória de Santo Antão, na Mesorregião da Mata Pernambucana. Em 2005, foram comercializadas na CEASA-PE uma média

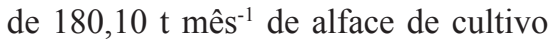
convencional (CEASA-PE, 2006).

$O$ cultivo da alface é realizado nos sistemas convencional, orgânico e, mais recentemente, hidropônico. Este último possibilita melhor controle ambiental, com menor incidência de pragas e doenças, facilidade nos tratos culturais, melhor programação e rendimento da produção. Esse controle é uma das principais vantagens conferidas pela hidroponia, dada a rapidez e a facilidade com que isso pode ser feito (Gualberto et al., 1999).

Um dos princípios básicos para produção vegetal, tanto no solo como em sistemas de cultivo sem solo, é o fornecimento de todos os nutrientes de que a planta necessita. A qualidade química e microbiológica da água usada também constitui fator de grande importância, principalmente no cultivo hidropônico. Nesse sistema, a absorção é geralmente proporcional à concentração de nutrientes na solução próxima às raízes, sendo muito influenciada pelos fatores ambientais, tais como salinidade, oxigenação, temperatura, $\mathrm{pH}$ da solução nutritiva, intensidade de luz, fotoperíodo, temperatura e umidade do ar (Silva, 2005).
Segundo Beninni et al. (2003) e Cometti et al. (2004b), um dos principais problemas enfrentados pelos produtores de alface, nos sistemas hidropônico e convencional, é o aparecimento da queima das bordas ou tip burn, que é um distúrbio fisiológico ocasionado pela deficiência localizada de cálcio, mesmo quando esse elemento encontra-se em níveis adequados no solo ou solução nutritiva. Esse nutriente é um dos constituintes do pectato de cálcio, composto que atua como elemento cimentante da parede celular e a sua deficiência leva a um enfraquecimento da estrutura e rompimento dos vasos lactíferos; com isso há liberação do látex, levando a um colapso celular e necrose do tecido (Fernandes \& Martins, 1999).

A queima das bordas, na maioria das vezes, está associada à deficiência de cálcio, induzida por condições edafoclimáticas adversas do meio, tais como estresse osmótico, normalmente 
encontrado em condições de controle inadequado da solução nutritiva, temperatura elevada tanto do ambiente, como da solução, luminosidade, altitude local e umidade relativa (Bernardes, 1997; Kopp et al., 2000; Pereira et al., 2005). Sua ocorrência pode evoluir de simples pontos escurecidos para a necrose total dos tecidos meristemáticos num estádio mais avançado. Esta necrose ocorre nas margens das folhas em desenvolvimento, na parte interna das plantas, ou seja, nos tecidos mais jovens. O efeito ocorre em muitas hortaliças, especialmente em alface e brássicas. As folhas sofrem uma constrição das bordas ao se tornarem adultas, reduzindo o valor de mercado do produto (Cometti, 2003).

A preferência do consumidor do Nordeste do Brasil é por alface de folhas lisas, soltas e verde escuras, que por sua vez é mais afetada pela queima das bordas no cultivo hidropônico (Magalhães et al., 2005). A queima das bordas das folhas é um defeito grave na classificação comercial da alface. Outros atributos importantes são o número de folhas e a massa da planta, que podem ser influenciados, entre outros fatores, pela cultivar, fotoperíodo e temperatura do ambiente de cultivo (Oliveira et al., 2004).

Nos últimos anos, tem-se observado crescente aumento na disponibilidade de cultivares de alface. Algumas são recomendadas para cultivo em ambiente protegido, onde as temperaturas elevadas constituem-se em fator limitante ao desenvolvimento desse sistema de produção em determinadas regiões, enquanto para outras não existem recomendações específicas.

O objetivo do trabalho foi avaliar o desempenho de cultivares de alface de folhas lisas, em cultivo hidropônico, sob dois níveis de condutividade elétrica.

\section{MATERIAL E MÉTODOS}

O trabalho foi desenvolvido no Dep ${ }^{\text {to }}$. de Agronomia, da UFRPE, em Recife-PE ( $\left.8^{\circ} 10^{\prime} 52^{\prime \prime} \mathrm{S} ; 34^{\circ} 54^{\prime} 47^{\prime \prime} \mathrm{W}\right)$, no período de setembro de 2005 a abril de 2006. O cultivo foi hidropônico NFT sob ambiente protegido com filme de polietileno transparente de $150 \mu \mathrm{m}$, aberto nas laterais. Foram realizados

Tabela 1. Composição da solução nutritiva proposta por Castellane \& Araújo (1995) e adaptada para as condições locais (composition of nutrient solution proposed by Castellane \& Araújo (1995) and adapted to local conditions). Recife, UFRPE, 2005/2006.

\begin{tabular}{|c|c|c|c|}
\hline \multirow{3}{*}{ Fertilizantes } & \multicolumn{3}{|c|}{ Idade das plantas, condutividade elétrica } \\
\hline & $\begin{array}{c}\text { Até } 10 \text { dias } \\
\left(\text { C.E. } 1,6 \mathrm{dS} \mathrm{m}^{-1}\right) \\
\end{array}$ & $\begin{array}{c}11 \text { a } 45 \text { dias } \\
\text { (C.E. 2,5 dS m }{ }^{-1} \text { ) }\end{array}$ & $\begin{array}{c}11 \text { a } 45 \text { dias } \\
\left.\text { (C.E. } 2,0 \mathrm{dS} \mathrm{m}^{-1}\right) \\
\end{array}$ \\
\hline & \multicolumn{3}{|c|}{$\left(\right.$ g $\left.1000 \mathrm{~L}^{-1}\right)$} \\
\hline Sulfato de magnésio & 285 & 520 & 390 \\
\hline Nitrato de potássio & 320 & 613 & 460 \\
\hline Nitrato de cálcio & 530 & 1000 & 750 \\
\hline Fosfato monopotássico & 100 & 200 & 150 \\
\hline Quelatec A/Z & 24 & 40 & 30 \\
\hline Acido bórico & 1,5 & 2 & 1,5 \\
\hline
\end{tabular}

dois experimentos, cada um com uma condutividade elétrica. Os tratamentos foram constituídos por cultivares de alface de folha solta e lisa (Babá de Verão (Isla), Floresta (Asgrow), Luisa (Horticeres), Manoa (Takii), Regina 579 (Sakata), Saia Véia (Hortivale) e Vitória Verdinha (Hortivale)). Adotou-se o delineamento de blocos casualizados, com três repetições, distribuídas no tempo, para otimização do espaço disponível. A parcela foi constituída por 20 plantas, sendo 16 na área útil. Foi utilizada a solução nutritiva de Castellane \& Araújo (1995), adaptada para as condições locais, cuja composição está apresentada na Tabela 1 .

No primeiro experimento, utilizouse a solução nutritiva com a condutividade elétrica de $2,5 \mathrm{dS} \mathrm{m}^{-1}$. Foi realizada a semeadura para a primeira e segunda repetições em 2 de setembro de 2005 e a avaliação final em 18 de outubro de 2005. Na terceira repetição, a semeadura foi realizada em 31 de outubro de 2005 e a avaliação final em 14 de dezembro de 2005. As médias mensais da temperatura máxima, em Recife, nos meses de setembro, outubro, novembro e dezembro foram, respectivamente, $30,30,31$ e $31^{\circ} \mathrm{C}$; e da temperatura mínima 22,23 , 24 e $24^{\circ} \mathrm{C}$ (Agritempo, 2006).

No segundo experimento, utilizou-se a solução nutritiva com a condutividade elétrica de 2,0 dS m $\mathrm{m}^{-1}$. Foi realizado o semeio para a primeira e segunda repetições em 7 de janeiro de 2006 e a avaliação final em 23 de fevereiro de 2006. Na terceira repetição, o semeio foi realizado em 11 de março de 2006 e a avaliação final em 26 de abril de
2006. As médias mensais da temperatura máxima, em Recife, nos meses de janeiro, fevereiro, março e abril foram, respectivamente, $31,32,32$ e $31^{\circ} \mathrm{C}$; e da temperatura mínima $24,24,23$ e $23^{\circ} \mathrm{C}$ (Agritempo, 2006).

A semeadura foi em placas de espuma fenólica com células de $2 \times 2$ x $2 \mathrm{~cm}$, umedecidas com água durante cinco dias. Após esse período, as plântulas foram levadas para mesa de desenvolvimento, na qual receberam solução nutritiva durante 10 dias. Após 15 dias, as plantas foram transferidas para perfis de polipropileno com diâmetro de 5,0 cm, no espaçamento de $10 \times 10 \mathrm{~cm}$, passando a receber solução nutritiva, no sistema hidropônico NFT, por mais 15 dias. Passado esse período, foram transferidas para perfis de $7,5 \mathrm{~cm}$ de diâmetro, no espaçamento de 25 x 25 cm por mais 15 dias, totalizando o ciclo cultural de 45 dias, no qual receberam solução nutritiva na fase de desenvolvimento (Tabela 1).

Foi utilizado como reservatório da solução nutritiva uma caixa de amianto revestida com impermeabilizante. A condução da solução para os perfis foi realizada com a utilização de uma eletrobomba com temporizador programado para permanecer ligado por 15 minutos e desligado por 15 minutos, de 6:00 até 18:00 horas e, apenas dois acionamentos de 15 minutos, às 22:30 e 2:30 horas. $\mathrm{O}$ volume da solução nos tanques foi mantido pela reposição de água e nutrientes diariamente. $\mathrm{O} \mathrm{pH}$ foi monitorado todos os dias com peagâmetro digital portátil e mantido entre 5,5 e 6,5. A condutividade elétrica da solução foi 
monitorada com condutivímetro digital portátil e mantida em 2,5 e 2,0 dS m $\mathrm{m}^{-1}$ para o primeiro e segundo experimentos, respectivamente, por meio da reposição de nutrientes e água.

A colheita das plantas com raízes realizou-se aos 45 dias após a semeadura, quando avaliaram-se a massa fresca das plantas inteiras, número de folhas, massa das folhas, massa do caule e raiz, comprimento do caule e o índice de queima das bordas.

Na avaliação da queima das bordas, foi utilizado um índice desenvolvido por Mckinney (1923), que contabiliza o número de folhas afetadas:

$$
\mathrm{IQB}=\frac{[(0 \mathrm{xA})+(1 \times \mathrm{A})+(2 \times \mathrm{A})]}{(\mathrm{NTF} 2)} \times 100
$$

, onde $I Q B$ é o Índice de Queima de Bordas, "0" é o número de plantas sem sintomas de queima, "A" é o número de folhas afetadas pela queima, "1" é o número de plantas com sintomas leves de queima, "2" é o número de plantas com sintomas severos de queima, e NTF é o número total de folhas, tendo-se o resultado final em porcentual e transformado em $\sqrt{(X+1)}$ para a análise estatística.
As características observadas foram submetidas à análise de variância individual e conjunta, utilizando o programa estatístico Genes (Cruz \& Regazzi, 1997), e as médias foram comparadas pelo teste de Tukey, a 5\% de probabilidade.

\section{RESULTADOS E DISCUSSÃO}

Não houve diferença significativa entre a massa fresca da planta inteira das cultivares submetidas à condutividade

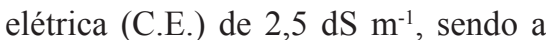
média geral de 172,2 g (Tabela 2). No

Tabela 2. Massa fresca da planta inteira com raiz e número de folhas de cultivares de alface cultivadas em solução nutritiva com condutividade elétrica de $2,5 \mathrm{dS} \mathrm{m}^{-1}$ e $2,0 \mathrm{dS} \mathrm{m}^{-1}$ (fresh weight of whole plant and number of leaves of lettuce cultivars grown in nutrient solution with electrical conductivity of 2,5 $\mathrm{dS} \mathrm{m}^{-1}$ and 2,0 $\mathrm{dS} \mathrm{m}^{-1}$ ). Recife, UFRPE, 2005/2006.

\begin{tabular}{|c|c|c|c|c|c|c|}
\hline \multirow{2}{*}{ Cultivares } & \multicolumn{3}{|c|}{ Massa fresca da planta inteira $(\mathrm{g})$} & \multicolumn{3}{|c|}{ Número de folhas planta-1 $^{-1}$} \\
\hline & $2,5 \mathrm{dS} \mathrm{m}^{-1}$ & $2,0 \mathrm{dS} \mathrm{m}^{-1}$ & Média* & $2,5 \mathrm{dS} \mathrm{m}^{-1}$ & $2,0 \mathrm{dS} \mathrm{m}^{-1}$ & Média \\
\hline Regina 579 & $188,5 \mathrm{a}^{* *}$ & $110,1 \mathrm{a}$ & $149,3 \mathrm{ab}$ & $38 \mathrm{a}$ & $31 \mathrm{a}$ & $35 \mathrm{a}$ \\
\hline Luisa & $156,7 \mathrm{a}$ & $46,5 b$ & $101,6 a b$ & $32 \mathrm{ab}$ & $20 \mathrm{bc}$ & $26 \mathrm{bc}$ \\
\hline Vit. Verdinha & $185,5 \mathrm{a}$ & $130,1 \mathrm{a}$ & $157,8 \mathrm{a}$ & $34 \mathrm{ab}$ & $29 \mathrm{a}$ & $31 \mathrm{ab}$ \\
\hline Floresta & $136,8 \mathrm{a}$ & $29,2 b$ & $82,9 \mathrm{~b}$ & $33 \mathrm{ab}$ & $17 \mathrm{c}$ & $24 \mathrm{bc}$ \\
\hline Babá de Verão & $162,7 \mathrm{a}$ & $89,3 \mathrm{a}$ & $125,9 \mathrm{ab}$ & $32 \mathrm{ab}$ & $25 \mathrm{ab}$ & $28 \mathrm{ab}$ \\
\hline Manoa & $182,0 \mathrm{a}$ & $91,4 \mathrm{a}$ & $136,7 \mathrm{ab}$ & $22 b$ & $19 b c$ & $21 \mathrm{c}$ \\
\hline Saia Véia & $192,5 \mathrm{a}$ & $39,2 b$ & $115,8 \mathrm{ab}$ & $35 \mathrm{ab}$ & $18 \mathrm{c}$ & $27 \mathrm{bc}$ \\
\hline Média & 172,2 & 76,5 & 124,3 & 32 & 22 & 27 \\
\hline CV (\%) & 27,9 & 19,4 & 31,9 & 15 & 10 & 15 \\
\hline DMS & 38,7 & & & 4,11 & & \\
\hline
\end{tabular}

*Dados obtidos através da análise conjunta dos dois experimentos; **Médias seguidas das mesmas letras, nas colunas, não diferem entre si, pelo teste de Tukey, a 5\% de probabilidade (*data from both experiments analysed together; **Values followed by the same letter in columns are not different through Tukey test at $5 \%$ ).

Tabela 3. Massa das folhas frescas e massa do caule e raiz de cultivares de alface cultivadas em solução nutritiva com condutividade elétrica de $2,5 \mathrm{dS} \mathrm{m}^{-1}$ e $2,0 \mathrm{dS} \mathrm{m}^{-1}$ (fresh mass of leaves and mass of stem and root of lettuce cultivars grown in nutrient solution with electrical conductivity of $2.5 \mathrm{dS} \mathrm{m}^{-1}$ and $2.0 \mathrm{dS} \mathrm{m}^{-1}$ ). Recife, UFRPE, 2005/2006.

\begin{tabular}{|c|c|c|c|c|c|c|}
\hline \multirow{2}{*}{ Cultivares } & \multicolumn{3}{|c|}{ Massa das folhas frescas $(\mathrm{g})$} & \multicolumn{3}{|c|}{ Massa do caule e raiz (g) } \\
\hline & $2,5 \mathrm{dS} \mathrm{m}^{-1}$ & $2,0 \mathrm{dS} \mathrm{m}^{-1}$ & Média* & $2,5 \mathrm{dS} \mathrm{m}^{-1}$ & $2,0 \mathrm{dS} \mathrm{m}^{-1}$ & Média \\
\hline Regina 579 & $129,6 \mathrm{a}^{* *}$ & $76,0 \mathrm{a}$ & $102,8 \mathrm{a}$ & $58,7 \mathrm{a}$ & $32,4 \mathrm{ab}$ & $45,5 \mathrm{ab}$ \\
\hline Luisa & $113,3 \mathrm{a}$ & $29,2 \mathrm{bc}$ & $71,2 \mathrm{a}$ & $52,9 \mathrm{a}$ & $15,7 \mathrm{~cd}$ & $34,3 \mathrm{abc}$ \\
\hline Vit. Verdinha & $133,0 \mathrm{a}$ & $87,6 \mathrm{a}$ & $110,3 a$ & $58,3 \mathrm{a}$ & $38,4 \mathrm{a}$ & $48,4 a$ \\
\hline Floresta & $93,4 a$ & $19,3 \mathrm{c}$ & $56,3 \mathrm{a}$ & $42,4 \mathrm{a}$ & $9,4 \mathrm{~d}$ & $25,9 \mathrm{c}$ \\
\hline Babá de Verão & $96,4 \mathrm{a}$ & $61,7 \mathrm{ab}$ & $79,0 \mathrm{a}$ & $52,7 \mathrm{a}$ & $25,3 \mathrm{bc}$ & $39,0 \mathrm{abc}$ \\
\hline Manoa & $134,3 \mathrm{a}$ & $65,8 \mathrm{a}$ & $100,0 \mathrm{a}$ & $53,7 \mathrm{a}$ & $24,3 \mathrm{bc}$ & $39,0 \mathrm{abc}$ \\
\hline Saia Veia & $130,4 \mathrm{a}$ & $26,8 \mathrm{c}$ & $78,6 a$ & $46,8 \mathrm{a}$ & $11,2 \mathrm{~d}$ & $29,0 \mathrm{bc}$ \\
\hline Média & 118,6 & 52,34 & 85,5 & 52,2 & 22,4 & 37,3 \\
\hline CV (\%) & 31,9 & 22,27 & 36,1 & 21,6 & 19,0 & 27,5 \\
\hline
\end{tabular}

*Dados obtidos através da análise conjunta dos dois experimentos; **Médias seguidas das mesmas letras, nas colunas, não diferem entre si, pelo teste de Tukey, a 5\% de probabilidade (*data from the both experiments analysed together; **Values followed by the same letter in columns are not different through Tukey test at $5 \%$ ). 
entanto, encontraram-se valores próximos daqueles com média de 183,65 g obtidos por Kopp et al. (2000) e Santos et al. (2000), trabalhando com a cultivar de alface Regina, sob condições ambientais diferentes, principalmente quanto aos fatores climáticos.

A cv. Vitória Verdinha destacou-se na massa fresca da planta inteira em condutividade elétrica de $2,0 \mathrm{dS} \mathrm{m}^{-1}$, não diferindo significativamente de Regina 579, Manoa e Babá de Verão (Tabela 2). Magalhães et al., (2005) trabalhando com a mesma cultivar e o mesmo nível de condutividade obtiveram 193,5 g de média da massa da planta inteira. Como foi proporcionado à cultivar uma C.E. de 2,0 dS m$~_{-1}$, possivelmente o ambiente e principalmente a temperatura podem ter contribuído para o melhor desenvolvimento da planta.

Em número de folhas, com C.E. de 2,5 dS m ${ }^{-1}$, destacou-se a cv. Regina 579, com 38 folhas planta ${ }^{-1}$, em relação à cv. Manoa, com 22 folhas planta ${ }^{-1}$. Esta cultivar apresentou desenvolvimento foliar mais lento, e isto provavelmente está relacionado com as características genéticas da cultivar. Em trabalhos realizados com condutividade elétrica em torno de 2,0 dS m $\mathrm{d}^{-1}$ a 2,64 dS m $\mathrm{d}^{-1}$, obtiveram-se número de folhas próximos aos encontrados neste trabalho (Fernandes et al., 2002; Magalhães et al., 2005).

Com relação ao número de folhas das alfaces cultivadas em solução nutritiva de 2,0 $\mathrm{dS} \mathrm{m} \mathrm{m}^{-1}$ de C.E., as cvs. Vitória Verdinha, Regina 579 e Babá de Verão não diferiram entre si, mas as duas primeiras foram superiores às demais, devido a essas cultivares apresentarem melhor desenvolvimento para as condições climáticas da região. A cv. Regina 579 apresentou o maior número de folhas, diferindo da cv. Floresta (Tabela 2).

Para a massa das folhas e massa do caule e raiz, as cultivares também não apresentaram diferenças significativas ao nível de $2,5 \mathrm{dS} \mathrm{m}^{-1}$ de C.E. Em relação à condutividade elétrica de 2,0 dS m ${ }^{-1}$, as cvs. Floresta e Saia Véia apresentaram as menores massas das folhas, respectivamente, sem diferirem das cvs. Luísa, Vitória Verdinha e Regina 579 que apresentaram as maiores massas frescas das folhas, não diferindo da cv. Manoa (Tabela 3). 'Saia Veia' e 'Floresta' apresentaram as menores massas de caule e raiz, enquanto 'Vitória Verdinha' e 'Regina 579' apresentaram as maiores massas.

Os comprimentos dos caules não foram diferentes significativamente, mas eles apresentaram expressivo alongamento, indicando tendência ao pendoamento precoce na solução nutritiva com 2,5 dS m${ }^{-1}$ de C.E. Segundo Ryder (1986) e Mendonça (2003), temperaturas acima de $20^{\circ} \mathrm{C}$ estimulam o pendoamento precoce, que é acentuado à medida que a temperatura aumenta.
As cultivares Vitória Verdinha, Regina 579 e Babá de Verão não diferiram entre si, mas apenas a primeira diferiu das demais. A cultivar que apresentou o maior comprimento do caule foi Vitória Verdinha, enquanto Saia Véia, apresentou o menor comprimento de caule com 2,0 dS m ${ }^{-1}$ de C.E. Dependendo da cultivar, temperaturas elevadas e dias longos podem ocasionar o pendoamento da alface. Após a indução do florescimento a planta emite o pendão floral, o que a torna imprópria para a comercialização devido à má formação da cabeça e ao gosto amargo que as folhas desenvolvem, em função do acúmulo rápido de látex.

Em 2,5 dS m-1 de C.E., o menor índice de queima das cultivares Luisa e Regina 579 é coerente com o observado por Magalhães et al. (2005), que avaliando a cultivar Regina, obtiveram $0 \%$ de incidência de queima das bordas. Regina é a cultivar de folhas soltas e lisas mais utilizada em cultivos hidropônicos em Pernambuco, justamente por ser tolerante à queima das bordas das folhas. Por outro lado, a cv. Manoa foi a mais suscetível à queima das bordas das folhas, enquanto as outras não diferiram estatisticamente entre si (Tabela 4).

$\mathrm{Na}$ análise conjunta com os dois níveis de solução nutritiva, para a massa fresca da planta inteira, as cvs. Vitória Verdinha e Floresta apresentaram diferenças significativas, enquanto as

Tabela 4. Comprimento do caule e índice de queima das bordas de cultivares de alface cultivadas em solução nutritiva com condutividade elétrica de 2,5 dS m $\mathrm{m}^{-1}$ e 2,0 dS m $\mathrm{d}^{-1}$ (stem length and rate of leaf-edge burning of lettuce cultivars grown in nutrient solution with electrical conductivity of $2.5 \mathrm{dS} \mathrm{m}^{-1}$ and $2.0 \mathrm{dS} \mathrm{m}^{-1}$ ). Recife, UFRPE, 2005/2006.

\begin{tabular}{|c|c|c|c|c|c|c|}
\hline \multirow{2}{*}{ Cultivares } & \multicolumn{3}{|c|}{ Comprimento do caule $(\mathrm{cm})$} & \multicolumn{3}{|c|}{ Índice de queima das bordas (\%) } \\
\hline & $2,5 \mathrm{dS} \mathrm{m}^{-1}$ & $2,0 \mathrm{dS} \mathrm{m}^{-1}$ & Média* & $2,5 \mathrm{dS} \mathrm{m}^{-1}$ & $2,0 \mathrm{dS} \mathrm{m}^{-1}$ & Média \\
\hline Regina 579 & $8,3 \mathrm{a}^{* *}$ & $6,2 \mathrm{ab}$ & $7,2 \mathrm{ab}$ & $1,0 \mathrm{~b}$ & $1,4 \mathrm{~b}$ & $0,5 \mathrm{bc}$ \\
\hline Luisa & $4,6 \mathrm{a}$ & $2,5 \mathrm{~b}$ & $3,6 b$ & $1,0 \mathrm{~b}$ & $1,0 \mathrm{~b}$ & $0,0 \mathrm{c}$ \\
\hline Vit. Verdinha & $6,7 \mathrm{a}$ & $9,2 \mathrm{a}$ & $8,0 \mathrm{a}$ & $1,9 \mathrm{ab}$ & $1,7 \mathrm{~b}$ & $2,7 \mathrm{bc}$ \\
\hline Floresta & $6,6 a$ & $2,0 \mathrm{~b}$ & $4,3 \mathrm{ab}$ & $2,0 \mathrm{ab}$ & $1,1 b$ & $1,8 b c$ \\
\hline Babá de Verão & $7,2 \mathrm{a}$ & $4,6 a b$ & $5,9 \mathrm{ab}$ & $2,9 \mathrm{ab}$ & $1,9 \mathrm{~b}$ & $5,5 \mathrm{abc}$ \\
\hline Manoa & $6,9 a$ & $3,5 b$ & $5,2 \mathrm{ab}$ & $3,8 \mathrm{a}$ & $3,0 \mathrm{a}$ & $12,5 \mathrm{a}$ \\
\hline Saia Véia & $4,2 \mathrm{a}$ & $1,9 \mathrm{~b}$ & $3,2 \mathrm{~b}$ & $3,9 \mathrm{a}$ & $1,4 \mathrm{~b}$ & $8,0 \mathrm{ab}$ \\
\hline Média & 6,4 & 4,3 & 5,3 & 2,3 & 1,7 & 4,4 \\
\hline CV (\%) & 39,1 & 41,3 & 43,9 & 38,0 & 22,1 & 40,2 \\
\hline DMS & 2,3 & & & 0,8 & & \\
\hline
\end{tabular}

*Dados obtidos através da análise conjunta dos dois experimentos; **Médias seguidas das mesmas letras, nas colunas, não diferem entre si, pelo teste de Tukey, a 5\% de probabilidade (*data from both experiments analysed together; **Values followed by the same letter in columns are not different through Tukey test at $5 \%$ ). 
demais não apresentaram diferenças significativas entre si. A cv. Manoa apresentou o menor número de folhas e a Regina 579, o maior número (Tabela 2).

Quanto à massa das folhas frescas, as cultivares não apresentaram diferenças significativas. Em relação à massa do caule e raiz, a cv. Vitória Verdinha apresentou maior massa diferindo das cvs. Saia Véia e Floresta que apresentaram as menores massas (Tabela 3).

As cultivares Saia Véia e Luisa apresentaram os menores comprimentos do caule, diferindo da cultivar Vitória Verdinha, que teve o maior. A cv. Luisa não apresentou índice de queima das bordas das folhas e Manoa foi a mais suscetível à queima das bordas das folhas (Tabela 4). Segundo Beninni et al. (2003), fatores que inibem o desenvolvimento da pressão radicular como alta intensidade luminosa, alta temperatura do ar, alta salinidade e condições que favoreçam o rápido crescimento promovem aparecimento de queima das bordas.

Nas condições em que este trabalho foi realizado, nenhuma cultivar se destacou no conjunto das características avaliadas, embora a cv. Manoa tenha apresentado o maior índice de queima de bordas das folhas, porem sem diferir estaticamente de "Saia Veia" e "Babá de Verão". A preferência dos produtores hidropônicos de Pernambuco é pela cv. Regina 579, seguida pela cv. Vitória Verdinha, evidenciando-se a falta de genótipos mais adaptados a essa condição de cultivo.

\section{AGRADECIMENTOS}

À FACEPE, pelo financiamento da pesquisa e pela bolsa de cooperação téc- nica concedida à primeira autora, através de recursos do Programa de Apoio ao Desenvolvimento Sustentável da Zona da Mata de Pernambuco (PROMATA).

\section{REFERÊNCIAS}

AGRITEMPO - Sistema de Monitoramento Agrometeorológico. 2006. Disponível em: http://www.agritempo.gov.br/agroclimas/ sumario?uf=PE. Acesso em: 02 de julho de 2006.

BENINNI ERY; TAKAHASHI HW; NEVES CSVJ. 2003. Manejo do cálcio em alface de cultivo hidropônico. Horticultura Brasileira 21: 605-610.

BERNARDES LJL. 1997. Hidroponia. Alface uma história de sucesso. Charqueada: Estação experimental de hidroponia "alface \& cia", p. 135.

CASTELLANE PD; ARAÚJO JAC. 1995. Cultivo sem solo: hidroponia. Jaboticabal: FUNEP. 43p.

CEASA-PE. Centro de Abastecimento Alimentar de Pernambuco. 2006. Disponível em: www. ceasape.org.br. Acessado em: 10 de fevereiro de 2006.

COMETTI NN. 2003. Nutrição mineral de alface (Lactuca sativa L.) em cultura hidropônica Sistema NFT. Rio de Janeiro: UFRRJ-Instituto de Agronomia. 106p. (Tese doutorado).

COMETTI NN; MATIAS GCS; ZONTA E; MARY W; FERNANDES MS. 2004a. Compostos nitrogenados e açúcares solúveis em tecidos de alface orgânica, hidropônica e convencional. Horticultura Brasileira 22: 748-753.

COMETTI NN; FRANTZ J; BUGBEE B. 2004b. A colheita antecipada pode prevenir queima de bordas (tipburn) em alface hidropônica cultivada em câmara de crescimento. In: CONGRESSO BRASILEIRO DE OLERICULTURA, 44. Anais eletrônicos... Campo Grande: SOB. Disponível em: www. niltoncometti.hpg.ig.com.br/index.htm. Acessado em: 20 de janeiro de 2006.

CRUZ CD; REGAZZI AJ. 1997. Modelos biométricos aplicados ao melhoramento genético. Viçosa: UFV. 390 p.

FERNANDES HS; MARTINS SR. 1999. Cultivo de alface em solo em ambiente protegido. Informe Agropecuário 20: 56-63.
FERNANDES AA; MARTINEZ HEP; PEREIRA PRG; FONSECA MCM. 2002. Produtividade, acúmulo de nitrato e estado nutricional de cultivares de alface, em hidroponia, em função de fontes de nutrientes. Horticultura Brasileira 20: $195-200$.

GUALBERTO R; RESENDE FV; BRAZ LT. 1999. Competição de cultivares de alface sob cultivo hidropônico "NFT" em três diferentes espaçamentos. Horticultura Brasileira 17: 155-158.

KOPP LM; SCHUNEMANN APP; BRACCINI NETO J; LEMOS CAS; SIMONETTI RB; SILVA ESB. 2000. Avaliação de seis cultivares de alface sob duas soluções nutritivas em sistema de cultivo hidropônico. Revista Faculdade de Zootecnia, Veterinária e Agronomia 7: 19-25.

MAGALHÃESAG; MESQUITAJCP; MENEZES D; RESENDE LV; MELO RO. 2005. Linhagens e cultivares de alface de folhas lisas sob cultivo hidropônico. In: CONGRESSO BRASILEIRO DE OLERICULTURA, 45. Resumos... Fortaleza: SOB (CD-ROM).

MENDONÇA IF. 2003. Cultivo hidropônico da alface sob diferentes relações nutricionais. Recife: UFRPE. 75p. (Tese mestrado).

MCKINNEY HH. 1923. Influence of soil temperature and moisture on infection of wheat seedlings by Helminthosporium sativum. Journal of Agricultural Research 26: 195 218.

OLIVEIRAACB; SEDIYAMA MAN; PEDROSA MW; GARCIA NCP; GARCIA SLR. 2004. Divergência genética e descarte de variáveis em alface cultivada sob sistema hidropônico. Acta Scientiarum 26: 211-217.

PEREIRA C; JUNQUEIRA AMR; OLIVEIRA SA. 2005. Balanço nutricional e incidência de queima de bordos em alface produzida em sistema hidropônico - NFT. Horticultura Brasileira 23: 810-814.

RYDER JE. 1986. Lettuce breeding. In: Breeding vegetable crops. Westport: The Avi Publishing Company: 433-474.

SANTOS O; SCHMIDT D; NOGUEIRA FILHO; LONDERO FA. 2000. Cultivo sem solo: hidroponia. Santa Maria, CCR/UFSM. 107p.

SILVA APP. MELO B. Hidroponia. Disponível em: http://www.fruticultura. iciag.ufu. br/ hidropo.htm. Acessado em: 03 de março de 2005. 